\title{
AXIAL RESIDUAL CAPACITY OF CIRCULAR CONCRETE-FILLED STEEL TUBE STUB COLUMNS CONSIDERING LOCAL BUCKLING
}

\author{
C. Yang ${ }^{1}$, Z.X. Yu ${ }^{1,2,3, *}$, Y.P. Sun ${ }^{1,3,4}$, L. Zhao ${ }^{5}$ and H. Zhao ${ }^{6}$ \\ ${ }^{1}$ School of Civil Engineering, Southwest Jiaotong University, Chengdu, China \\ ${ }^{2}$ National Engineering Laboratory for prevention and control of geological disasters in land transportation, \\ Chengdu, China \\ ${ }^{3}$ China-Japan Resilient and Sustainable Concrete Structure Research Center, Chengdu, China \\ ${ }^{4}$ Department of Architecture, Graduate School of Engineering, Kobe University, Kobe, Japan \\ ${ }^{5}$ Department of Civil and Environmental Engineering, The Hong Kong Polytechnic University, \\ Hong Kong, China \\ ${ }^{6}$ State Key Laboratory of Geohazard Prevention and Geoenvironment Protection, \\ Chengdu University of Technology, Chengdu, China \\ *(Corresponding author: E-mail: yzxzrq@swjtu.edu.cn)
}

Received: 19 June 2017; Revised: 2 September 2017; Accepted: 17 November 2017

\begin{abstract}
This paper proposes a superposition method considering local buckling to estimate the residual capacity of circular concrete-filled steel tube stub columns (CFSTs) under axial compression based on substantial experimental data, consisting of 3 recently conducted tests as well as 150 test results from available literature. The proposed approach accounts for the influence of local buckling of the steel tube on confining effect, by introducing a coefficient to reduce the compressive strength of concrete in the post-buckling stage. Three specimens, including a bare steel stub column with circular hollow section (CHS), a CHS with concrete restraint and a CFSTs, were tested to investigate the contribution of concrete on the local buckling. Further, the mechanical model of steel tube was established and the design equations for residual bearing capacity of the tube were derived. The nominal load-shortening curves of the concrete core are extracted from 150 collected experimental curves of the CFSTs, with different parameters such as diameter-to-thickness $(D / t)$ ratio, yield strength $f_{\text {sy }}$ and concrete strength $f_{\text {cp. }}$. The variation of the stiffness degradation in the curves indicates that the effect of local buckling on both ductility and residual compressive strength of the concrete core are correlated with the section type of the steel tube. The residual compressive strength decreases exponentially with the increase of the generalized outer diameter-to-thickness ratio.
\end{abstract}

Keywords: CFST, stub column, circular section, axial residual capacity, superposition method, local buckling

DOI: 10.18057/IJASC.2018.14.3.11

\section{INTRODUCTION}

With the increasing of natural disasters occurred during the past decades [1-3], the study on the analysis and design of engineering structures not only focus on the normal structural service condition, but also on the ultimate capacity [4-7] and the post-buckling stages to improve the anti-collapse performance of structures and members, especially the load-bearing columns [8-10].

In view of the outstanding compressive resistance and ductility, CFSTs have been widely used as load-bearing columns in high-rise buildings. Generally, a portion of compressive load will be borne by the steel tube, which results in the reduction of confining effect and induces local buckling. Consequently, the ductility and composite effects of CFSTs will be significantly influenced, which finally affect the residual bearing capacity of the CFSTs.

For the ultimate bearing capacity, the CFSTs is generally considered as a unified element or a composite element, corresponding to unified method and superposition method, respectively. 
However, in the post-buckling stage, the entire cross-section of the CFST no longer satisfies the plane section assumption, and many mechanical behaviours, such as passive confinement and local buckling, would be significant in the process of the interaction, which means that the working mechanism of the CFST depends on the cooperativity of the steel tube and concrete rather than consistency. Therefore, it is better to regard the CFST as a composite element.

Besides, the composite response of CFSTs in compression is complicated due to the local buckling of the steel tube. On one side, the residual strength and deformation of the steel tubes are strongly related to the buckling strain [11], but the local buckling mode will be influenced by the concrete restraint. On the other side, because the Poisson's ratio of steel tube is higher than that of concrete in elastic range, compared with the steel tube confined concrete stub column (STCCs), the compressive stress in the steel tube of the CFST leads to the development of the confining stress in a lagging manner throughout the load history. For thin-walled CFSTs and the CFSTs with high strength concrete, the passive confinement often appears after the local buckling of steel tubes [12-14]. Many researches showed that the CFST with high strength concrete exhibits a steep degradation of stiffness in the early post-buckling stage [14-16], which means that the confinement from the steel tube cannot continue to effectively keep a well compressive strength of the concrete core. In summary, the mechanical model of the confined concrete of STCCs is not suitable for the concrete core of CFST.

The composite element theory has been adopted by Eurocode 4 and many researchers $[18,36]$ to estimate the confining effect before buckling of steel tube. The theory estimates the axial capacity of CFST column by combining the axial capacities of steel tube and concrete. However, most of the studies do not pay attention to the residual capacity of CFST column in the post-buckling stage, but it is valuable in the study of structural anti-collapse design. Compared with long column, the confining effect of short column before the buckling of steel tube can be neglected, when buckling occurs, the lateral deformation of steel tube will strengthen the confining effect, the residual capacity of CFST short column will be enhanced significantly, and the compressive capacity of the steel tube will decrease due to the buckling effect. Therefore, the confining effect and the degeneration of the axial capacity of the steel tube affect the residual capacity of CFST short column, which leads to the result that estimation of the residual capacity becomes very complicated, and it is necessary to take into account the influence of the non-linear factors when using the superposition method.

The CFSTs studied in this paper requires the entire cross section loaded, but only relying on the concentric compressive tests of CFST, the mechanical curves of the concrete core and the steel tube are difficult to measure respectively, and the effect of lateral restraint on local buckling of the steel tube is also not easy to clarify. Therefore, the paper carried out three axially compressive experimental tests of short columns, including a bare CHS, a CHS with concrete restraint, and a CFST, with the similar material parameters and the same size. The mechanical model of the steel tube was proposed based on the analysis of the measured data.

Furthermore, based on 150 experimental load-shortening curves from the previous CFST tests, the unified various ductile characteristics of the concrete cores in CFSTs were clearly exhibited with the consideration of the local buckling of steel tube. The work can predict the residual bearing capacity of CFSTs in a simple way.

Based on the above analysis, the calculation expressions of axial residual capacity of CFSTs considering local buckling were derived by superposition method, using a coefficient to reduce the compressive strength of concrete in the post-buckling stage. 


\section{MECHANICAL MODEL OF STEEL TUBE}

The mechanical behaviour of the steel tube in CFST is affected by the concrete core, the influence of which is mainly reflected in the local buckling. Experimental researches on the thin-walled CFSTs have shown that the pattern of local buckling of the steel tubes is an outwards buckle instead of wrinkled buckle [17-18]. O'Shea and Bridge [14] pointed out that the local buckling affects the strength of the steel tube in CFSTs. Some Japanese researchers [18] considered the axial stress-strain relationship of the steel tube in CFST as an elastic-perfectly plastic model as shown in Figure 1. Obviously, the model ignores the local buckling, which causes the decrease in axial bearing capacity of the steel tube. Wang and Zhang [19] proposed a steel tube model including a descending portion depending on the steel ratio, yield strength of the steel tube and unconfined compressive strength of the concrete core. However, their model only focuses on the yielding of the steel tube. Overall, the effective contribution of the concrete core on the mechanical model of the steel tube in CFST is still a difficult problem.

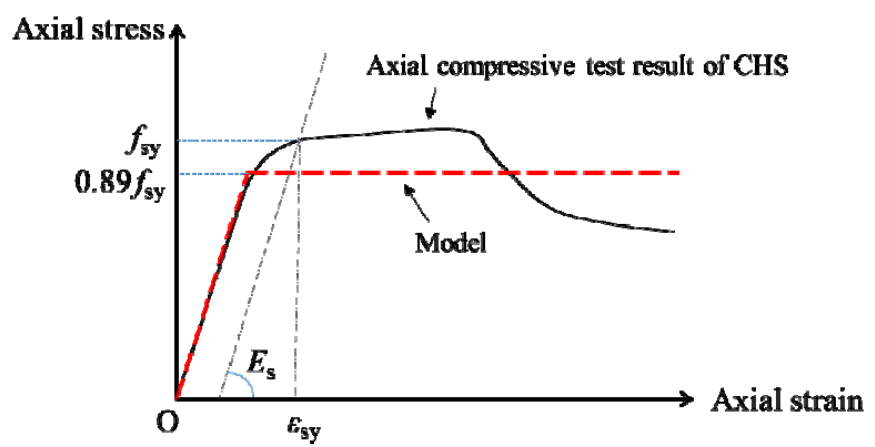

Figure 1. Axial Stress-strain Model of the Steel Tube in CFST

O'Shea and Bridge [20] conducted a series of experimental studies on CHS stub columns, with $D / t$ ratio ranging from 55 to 220. These studies included axially compressive tests of CHSs with and without internal restraint.
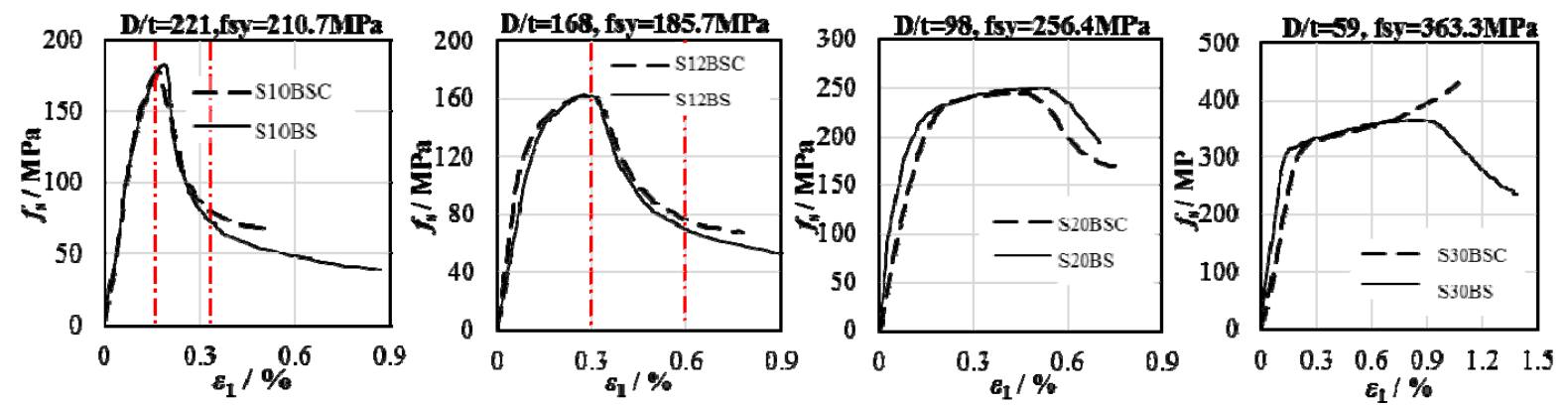

Figure 2. Results of CHSs with and without Internal Restraint under Axial Compression

All the complete experimental curves of the CHSs, as shown in Figure 2, exhibit a similar process in the ascending portion, regardless of whether concrete filled the tubes or not. Moreover, except the column labelled S30BSC exhibiting strain hardening in the post-ultimate stage because the filled concrete was touched by the loading platen as stated in the original, the developments of degradation stiffness in the other comparative curves are nearly in perfect agreement within the range of twice $\varepsilon_{\mathrm{sm}}$. The stiffness appears to be improved for strain beyond $2 \varepsilon_{\mathrm{sm}}$, probably because the concrete shares some axial load gradually, as in the case of the last column. 
Johansson and Gylltoft [17] carried out a set of axially compressive tests of a CHS without any restraint and a thick-walled CFST loading the steel tube firstly. According to the comparison of the experimental results between the two types of the columns as shown in Figure 3, a little difference of the structural compressive stress-strain relationships was also exhibited prior to the compression of the concrete in CFST.

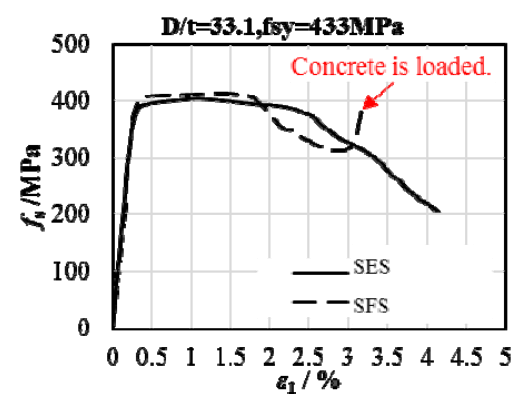

Figure 3. Results of a CHS and a CFST Test under Axial Compression from Reference [17]

The experimental curves using the solid lines in Figure 2 and Figure 3 are from the bare CHSs. According to the experimental results of the above comparative tests, one interesting conclusion can be drawn: the concrete filled in the CHS has little effect on the local buckling strength and deformation for the CHSs under axial compression. However, it is still a problem that the effect of concrete dilatation on the steel tube in CFSTs when considering the concrete to withstand the axial load. Therefore, the paper designed three experimental specimens to study the restraint effect from the concrete core to the steel tube of CFSTs.

\subsection{Setup and Results of the Tests}

Three short specimens were tested under concentric axial loading. As shown in Figure 4, the first column was a bare CHS labelled CHS-125; the second was a CHS partially filled in concrete labelled CHS-125-C; and the third was a CFST labelled CFT-125-C30. To obtain a reliable load-axial shortening curve in the post-buckling stage, about $100 \mathrm{~mm}$ in the specimen CHS-125-C was left unfilled. The axial displacements of the specimens were recorded by the linear variable differential transducers (LVDTs) in four directions. To study the interaction between the core and the steel tube, nine vertical and nine horizontal electrical strain gauges, arranged $120^{\circ}$ apart, were attached at three heights of each specimen. All the tests were carried out with a $10 \mathrm{MN}$ electro-hydraulic servo pressure testing machine.

The outer diameter $(D)$ and thickness $(t)$ of the steel tubes for all the specimens were $376 \mathrm{~mm}$ and $3.04 \mathrm{~mm}$ respectively, and the length $(L)$ was 3.0 times of $D$. The yield strength of the steel tubes was 305.3 MPa. The unconfined compressive strength of the concrete core in the CFST was about 39.6 MPa.

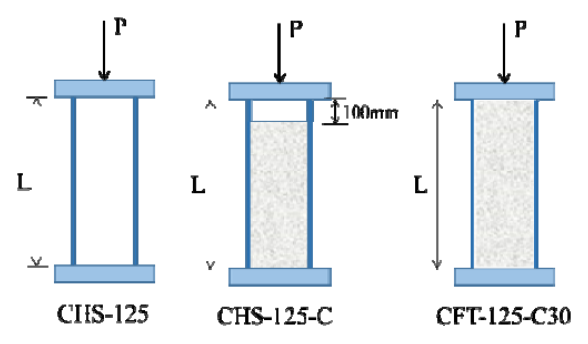

(a) Experimental specimens

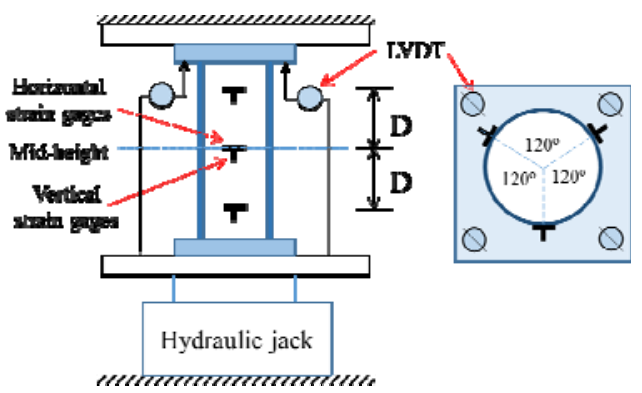

(b) Instrumentation of the tests

Figure 4. Design of the Tests 
The structural behaviours of the three specimens are represented in Figure 5. When the load reaches a peak, the wrinkled buckles of CHS-125 distributed at a distance of one diameter from the middle height. CHS-125-C occurred an outwards buckle in the unfilled region at the shortening strain of 0.0018 , and then the peak load arrived when the shortening strain was 0.0022 . At the 0.002 of the shortening strain when the specimen was still in the elastic stage, an outwards buckle appeared near the upper end of the CFT-125-C30, and the peak load of the CFST was at the shortening strain of 0.0063. The load-axial shortening responses between the CHS-125 and CHS-125-C are similar as the experimental curves shown in Figure 5.
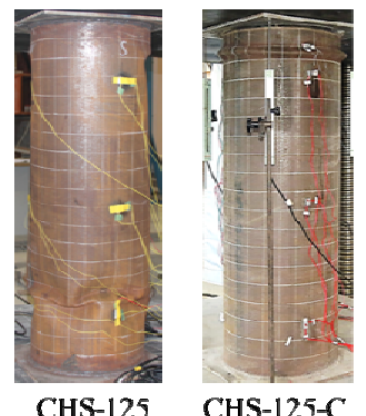

CHS-125-C

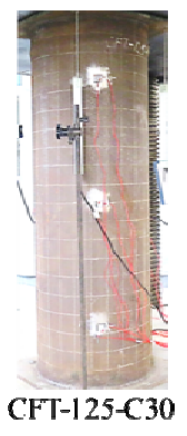

(a) Buckling modes
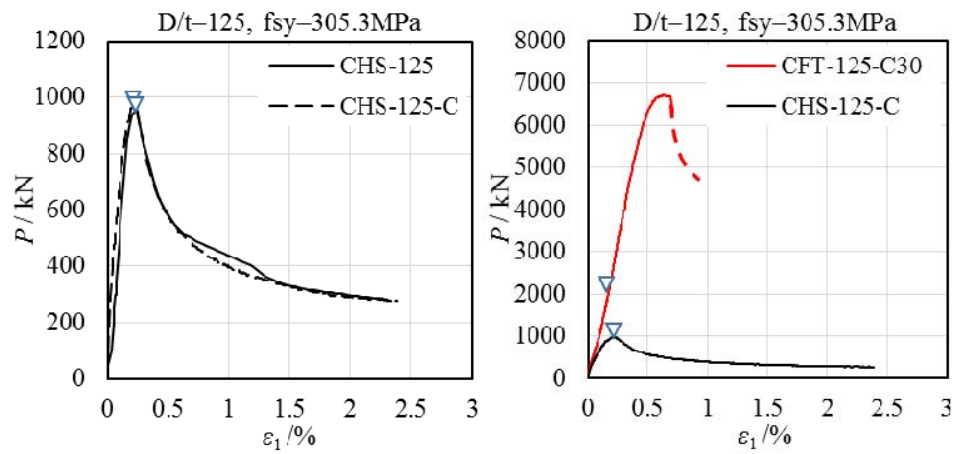

(b) Load-axial shortening responses

Figure 5. Structural Behaviours of the Three Specimens

Based on the information from the strain gauges, the development of the material properties of the three specimens are drawn in Figure 6 and Figure 7. Figure 6 shows the horizontal and vertical strain in mid-height for the two CHSs and the CFST. Both of the principal strains have a similar development before the tube buckle. Comparing the descending portion between the CHS-125 and the CHS-125-C, the unloading behaviour caused by the local buckling in CHS-125-C has not been significantly displayed, since the vertical strain of the CHS-125-C shows a gentle decline. Because the concrete filled in the CHS-125-C is not loaded, the only reason to explain the phenomenon is that the bond between the concrete and the inner wall of the steel tube preventing the stress unloading.

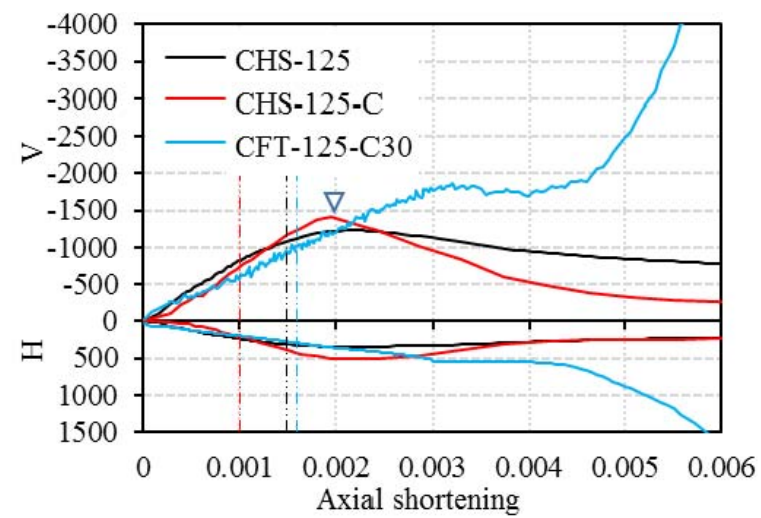

Figure 6. Principal Strains of the Three Specimens at Mid-height

However, for the CFT-125-C30, the principal strains for the steel tube exhibit a steep increase in the non-local buckling region after the axial shortening strain reaches 0.004. Based on Figure 7, the farther away from the buckling, the more obvious the rapid development trend of the principal strains became. The above phenomenon clear implied that the dilatation of the concrete core leads to the growth of the horizontal strain for the steel tube, which was accompanied by a further compression in the vertical direction. On the other side, the analysis of the measured results showed 
that the steel tube of CFT-125-C30 yielded before the local buckling. As shown in Figure 7, the three dotted lines represent the different starting position of the steel yield at corresponding heights of the specimen.

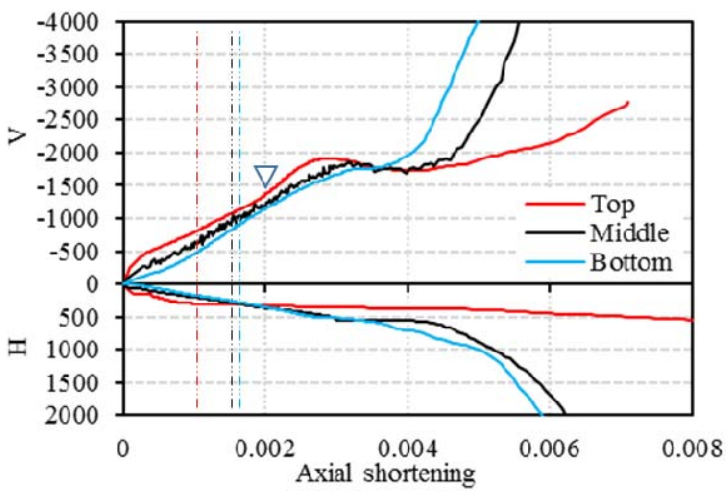

(a) Principal strains along the height

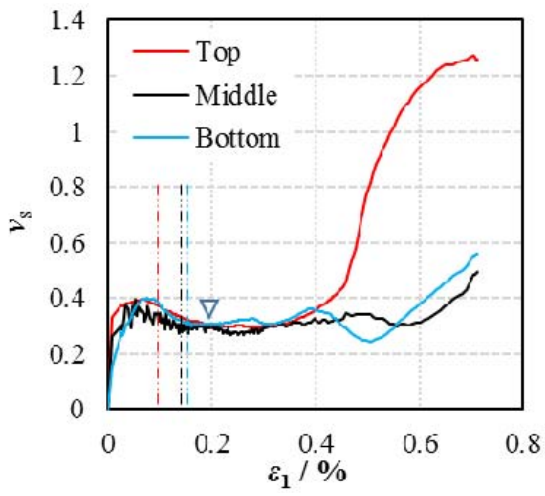

(b) Dilatations

Figure 7. Development of Material Properties of the Steel Tube in CFT-125-C30

In summary, the interaction between the steel tube and the concrete core in CFT-125-C30 determines the development of the steel strength, and the passive confinement from the steel tube to the concrete core has displayed since the local buckling.

\subsection{Compressive Stress-Strain Relationship}

Based on the above experimental results, Table 1 lists the peak stress $f_{\mathrm{sm}}$ of the steel tubes and the corresponding the peak stress $\varepsilon_{\mathrm{sm}}$, except that the $\varepsilon_{\mathrm{sm}}$ of CFT-125-C30 corresponds to the buckling. All the deviations of $f_{\mathrm{sm}}$ between the CHSs with and without the internal restraint are very small, and have no regularity with the $D / t$ ratio increasing. The most of deviation of $\varepsilon_{\mathrm{sm}}$ for the CHSs and CFSTs are within $20 \%$, and the scattering results from the instability of plastic flow of the material as the steel yields.

Table 1. The Peak Stress and Peak Strain of the Steel Tubes

\begin{tabular}{ccccccc}
\hline Group & Name & $D / t$ & $f_{s m}(\mathrm{MPa})$ & $\varepsilon_{s m}(\%)$ & $\begin{array}{c}\text { Deviation ratio } \\
\text { of } f_{s m}\end{array}$ & $\begin{array}{c}\text { Deviation ratio } \\
\text { of } \varepsilon_{s m}\end{array}$ \\
\hline 1 & SES & 33.1 & 404.5 & 1.08 & & \\
& SFS & 33.1 & 414.0 & 1.48 & $2.35 \%$ & $37.04 \%$ \\
2 & B30BS & 58.5 & 371.4 & 0.85 & & $-18.82 \%$ \\
& B30BSC & 58.5 & 363.5 & 0.69 & $-2.13 \%$ & $-19.23 \%$ \\
3 & S20BS & 98 & 248.1 & 0.52 & & $-8.33 \%$ \\
\multirow{2}{*}{4} & S20BSC & 98 & 244.8 & 0.42 & $-1.33 \%$ & $-16.7 \%$ \\
& CHS-125 & 114.6 & 249.7 & 0.24 & & \\
& CHS-125-C & 114.6 & 253.6 & 0.22 & $1.56 \%$ & $0.00 \%$ \\
& CFT-125-C30 & 114.6 & & $0.20 *$ & & $-10.53 \%$ \\
\hline \multirow{2}{*}{6} & S12BS & 168 & 162.7 & 0.29 & & \\
& S12BSC & 168 & 163.0 & 0.29 & $0.18 \%$ & \\
& S10BS & 220.9 & 181.8 & 0.19 & & \\
& S10BSC & 220.9 & 178.0 & 0.17 & $-2.09 \%$ & \\
\hline
\end{tabular}

Note: The value with * represents the local buckling stress of the steel tube in CFT-125-C30. 
From the above analysis process of the principal strains of the steel tubes, the compressive stress-axial strain relationship of the CHSs with or without the internal restraint is not affected by the buckling modes. Depended on the dilatation of the steel tube, the concrete core of the CFST promotes the utilization of the material strength in the stress distribution of the cross-section, which implies that the interaction between the steel tube and the concrete core mainly affect the passive confinement in the post-buckling stage rather than the axial stress of the steel tube.

In summary, the paper uses the complete compressive stress-strain relationship of the CHSs to analysis the mechanical behaviour of the steel tube in CFSTs.

Yang [11] proposed a single parameter model of a complete compressive stress-strain curve for CHSs, given by Eq. 1, and introduced a simple calculation method to obtain the continuous strength $f_{\mathrm{sm}}$ of CHS in compression, given by Eq. 2 , which has the same acceptable accuracy and a wide application range as the result from Eq. 1. Both of these equations are based on regression analysis of 48 available experimental data on columns.

$$
\begin{aligned}
& f_{s}= \begin{cases}E_{s} \varepsilon_{s}\left(Q+\frac{1-Q}{\left(1+\left|\varepsilon_{s} / \varepsilon_{c h}\right|^{6}\right)^{1 / 6}}\right) & \varepsilon_{s} \leq \varepsilon_{s m} \\
\frac{A}{\varepsilon_{s}+B} & \varepsilon_{s}>\varepsilon_{s m}\end{cases} \\
& \varepsilon_{s m}=\frac{f_{s y}}{E_{s}} \cdot \frac{0.25}{\alpha^{1.3}} \\
& Q=0.03\left(\varepsilon_{s m} \%\right)^{-0.63} \\
& \varepsilon_{c h}=\frac{S f_{s y}-Q E_{s} \varepsilon_{c m}}{(1-Q) E_{s}} \\
& f_{s m}=S \cdot f_{s y}=\frac{1}{0.82+1.22 \alpha} \cdot f_{s y} \\
& \alpha=\frac{D}{t} \frac{f_{s y}}{E_{s}}
\end{aligned}
$$

In the above equations, $\alpha$ is the generalized outer diameter-to-thickness ratio. $Q$ and $\varepsilon$ sh represent the second stiffness and the characteristic strain in the ascending portion. $A$ and $B$ governing the descending portion can be solved from a system of linear equations after the determination of the peak coordinates $\left(\varepsilon_{\mathrm{sm}}, f_{\mathrm{sm}}\right)$ and the residual stress $f_{\mathrm{s} \text {,res. }}$.

The residual stress $f_{\mathrm{s} \text {,res }}$ of CHSs is highly correlated with the peak stress $\varepsilon_{\mathrm{sm}}$, as described below, corresponding to the axial residual strain $\varepsilon_{\text {res }}$ of 0.04 , where the decline of steel tubes in the compressive stress becomes sufficiently gentle, based on the available experimental data, as mentioned in reference [11]. 


$$
f_{s, r e s}=R \cdot f_{s y}=\left(0.12+0.23 \varepsilon_{s m} \%\right) \cdot f_{s y} \leq f_{s y}
$$

Note that $\varepsilon_{\mathrm{sm}}$ in the civil engineering structures is usually not less than $0.2 \%$, except for certain non-compact sections with large $D / t$ ratio well exceeding the specified upper limit corresponding to local buckling. This information indicates that the concrete core in CFSTs should receive certain confinement before severe damage occurs.

\subsection{Principal Stresses}

Based on the research of the experimental tests, the steel tube of the CFT-125-C30 yielded prior to the local buckling. The result was also verified by many available tests including [12-14, 21]. It is useful to confirm the plane stress state of the steel tube in CFSTs, and to study the interaction between steel tubes and concrete cores in the post-buckling stage.

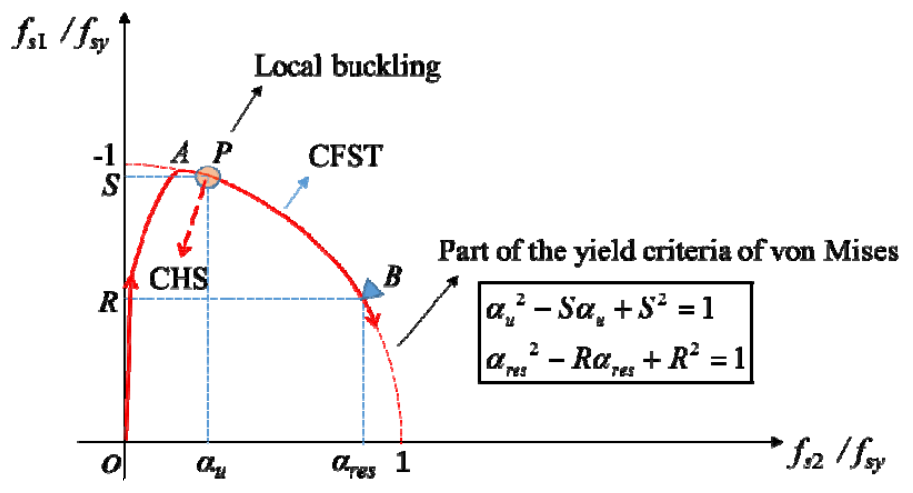

Figure 8. Development of the Plane Stress State of the Steel Tube

The process of principal stresses for steel tubes of CFSTs is shown in Figure 8. Due to the concrete dilatation, the principal stresses for the overall CFST can be further developed after local buckling of the steel tube. The plane stress state is assumed to obey the yield criteria of von Mises.
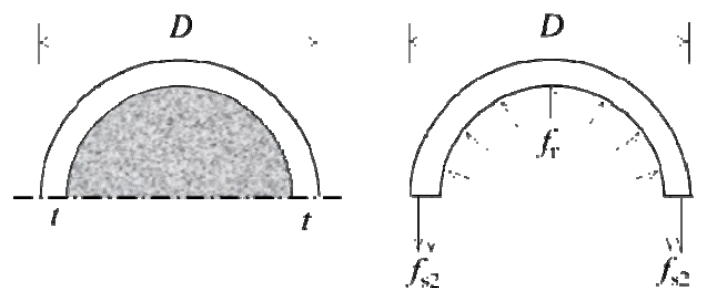

Figure 9. Equilibrium Relationship between the Horizontal Stress $f_{\mathrm{s} 2}$ and the Confining Stress $f_{\mathrm{r}}$

Finally, the confining stress $f_{\mathrm{r}}$ of the steel tube can be obtained based on the equilibrium relationship in the cross-section, as shown in Figure 9, and the function is:

$f_{r}=\frac{2 t}{D-2 t} f_{s 2}$

Relying on the mechanical model in the vertical direction, the load-axial shortening curve for the concrete core should be extracted from the experimental structural curve of the CFST. And the compressive strength of the concrete core in the post-buckling stage can be obtained based on the confining stress $f_{\mathrm{r}}$, which is used to research the residual bearing capacity of the CFSTs. 


\section{ANALYTICAL INVESTIGATION OF CONCRETE}

Brittle-ductile transition behaviour of the concrete core in CFSTs depends on both the $D / t$ ratio of steel tube and $f_{\text {cp. }}$. In general, the CFSTs have two typical failure modes [22], as shown in Figure 10. To investigate the reliable compressive capacity of the concrete core of the CFST in the post-buckling, the confining effect is systematically studied depending on the key influencing factors, such as the section type of the steel tube and the concrete strength $f_{\mathrm{c}}$ as well as the local buckling.

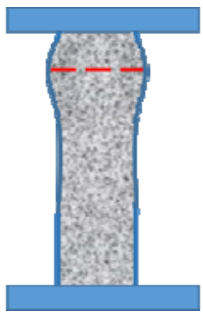

(a) Splitting failure

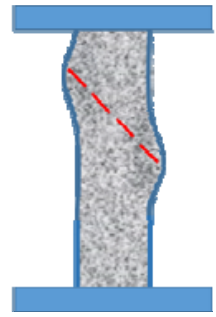

(b) Shear and sliding failure

Figure 10. Two Typical Failure Modes of CFSTs under Compression

\subsection{Influencing Factors of Confinement without Considering the Local Buckling}

It is meaningful to determine the confinement effect by studying the influence of the potential factors. To avoid the influence of local buckling in CFSTs, the steel tube confined concrete columns (STCCs) are selected as research objects. To this, 85 experimental data sets of STCCs in compression were collected from the references [17, 21, 23-30], with a wide range of structural factors: $D / t$ ratio ranges from 10.1 to $220.9, f_{\text {sy }}$ ranges from 185.7 to $433 \mathrm{MPa}$, and $f_{\text {cp }}$ ranges from 8.0 to $101.5 \mathrm{MPa}$. The key data of several typical STCCs are shown in Table 2, where $f_{\text {cp }}$ is the compressive strength of the same size concrete cylinders without confinement.

Table 2. Dimensions and Properties of STCCs in the Tests from Literature

\begin{tabular}{cccccccc}
\hline$D(\mathrm{~mm})$ & $D / t$ & $f_{\text {sy }}(\mathrm{MPa})$ & $f_{\text {cp }}(\mathrm{MPa})$ & $N_{\text {u,exp }}(\mathrm{kN})$ & $f_{\text {cc0 } \exp }(\mathrm{MPa})$ & $K_{\exp }$ & Ref. \\
\hline 159 & 33.1 & 433 & 54.6 & 2220 & 126.7 & 2.32 & {$[17]$} \\
166 & 33.2 & 274.6 & 29.1 & 1888 & 98.8 & 3.39 & {$[21]$} \\
121 & 10.1 & 294.2 & 41.0 & 1873 & 253.6 & 6.18 & \\
121 & 10.1 & 294.2 & 8.0 & 2354 & 318.7 & 39.64 & \\
150 & 50.0 & 254 & 61.8 & 1910 & 117.3 & 1.9 & {$[23]$} \\
210 & 70.0 & 254 & 59.7 & 3390 & 103.8 & 1.74 & \\
200 & 100.0 & 263 & 59.9 & 3000 & 99.5 & 1.66 & \\
133.3 & 26.6 & 351 & 73.5 & 2004 & 167.9 & 2.28 & {$[24]$} \\
158.9 & 31.0 & 356.3 & 59.0 & 3108 & 179.2 & 3.04 & {$[25]$} \\
152.4 & 48.8 & 347 & 45.2 & 2456 & 146.5 & 3.24 & {$[26]$} \\
159 & 31.8 & 390 & 29.3 & 2120 & 121.6 & 4.15 & {$[27]$} \\
101.8 & 34.6 & 319.5 & 37.6 & 724.2 & 100.3 & 2.67 & {$[28]$} \\
101.8 & 17.9 & 304.8 & 19.4 & 961.4 & 149.9 & 7.71 & \\
190 & 220.9 & 210.7 & 35.9 & 1240 & 44.6 & 1.24 & {$[29]$} \\
165 & 58.5 & 363.3 & 46.1 & 1759 & 88.2 & 1.91 & \\
190 & 220.9 & 210.7 & 70.1 & 2433 & 87.4 & 1.25 & \\
190 & 168.1 & 185.7 & 53.0 & 1862 & 67.3 & 1.27 & \\
190 & 125.0 & 306.1 & 75.3 & 2870 & 104.6 & 1.39 & \\
114.3 & 22.0 & 376.3 & 52.2 & 1483 & 175.0 & 3.35 & {$[30]$} \\
\hline
\end{tabular}


In Table 2, the strength enhancement factor $K_{\exp }$ is the ratio of $f_{\mathrm{cc} 0, \exp }$ to $f_{\mathrm{cp}}$, where $f_{\mathrm{cc} 0 \text {,exp }}$ is the ultimate compressive strength of the confined concrete defined as the ratio of the measured peak load $N_{\text {u,exp }}$ to initial pressure area of concrete $A_{\text {c. }}$ Undoubtedly, the value of $K_{\exp }$ reflects the highest level of confinement provided by the steel tube to the concrete. Figure 11a shows the relationships of $K_{\exp }$ and three primary experimental variables of STCCs. Although $f_{\text {sy }}$ is observed to be almost irrelevant to $K_{\exp }$, the confinement from the steel tube diminishes with the increasing of the $D / t$ ratio, the upper limit of $K_{\exp }$ decreases with the increasing of $D / t$ ratio in a power function when the $D / t$ ratio is more than 20, as shown in the second panel of Figure 11a. A similar analysis result in regard to $f_{\text {cp }}$ is also reflected in the third panel of Figure 11a.
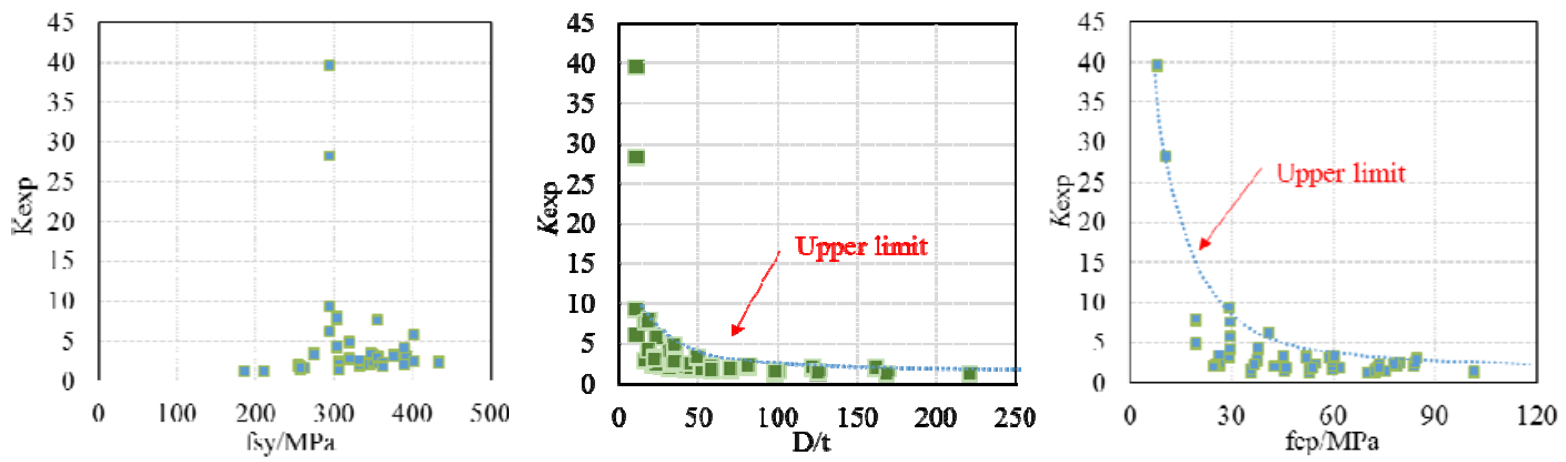

(a) Relationships between $K_{\exp }$ and the Primary Experimental Variables of STCCs
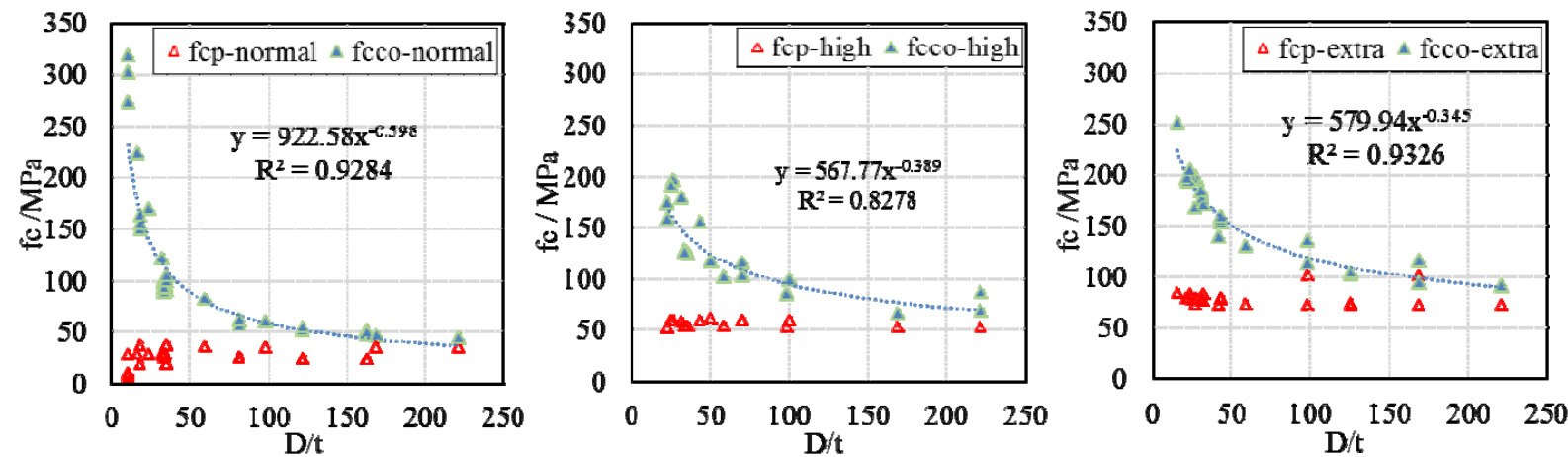

(b) Influence of $D / t$ ratio to $f_{\mathrm{c}}$

Figure 11. Influence of the Primary Variables for Confinement

Figure $11 \mathrm{~b}$ reveals the more specific influence relationships among $D / t$ ratios and different strength ranges of $f_{\text {cp. }}$ The relationship between $D / t$ ratio and $f_{\text {cc0,exp }}$ exhibits a clear power function with a

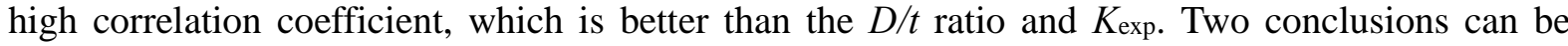
obtained from Figure 11b that the enhancement of concrete strength in STCCs is (1) obvious for the specimens unless the $D / t$ ratio is greater than 100 and (2) becoming worse with the increasing of $f_{\text {cp. }}$.

\subsection{Influence of Local Buckling on the Confining Effect}

To gain a unified various ductile characteristics of the concrete core with different failure modes, 150 experimental load-shortening curves from the previous tests of the CFSTs are collected, as shown in Table 3. Based on the complete compressive mechanical model of the steel tube, the nominal load-axial shortening curves of the concrete core should be extracted from the experimental curves of the CFSTs, which have considered the effect of the local buckling. 
Table 3. Summary of the available Test Specimens for CFSTs

\begin{tabular}{cccccc}
\hline$D(\mathrm{~mm})$ & $D / t$ & $\alpha$ & $f_{\text {sy }}(\mathrm{MPa})$ & $f_{\text {cp }}(\mathrm{MPa})$ & Ref. \\
\hline $108 \sim 133$ & $18.1 \sim 125$ & $0.038 \sim 0.799$ & $232 \sim 429$ & $83.4 \sim 97.2$ & {$[13]$} \\
$108 \sim 450$ & $15.2 \sim 220.9$ & $0.061 \sim 0.202$ & $283 \sim 834$ & $21.8 \sim 88$ & {$[18]$} \\
$152 \sim 273$ & $15.2 \sim 36.9$ & $0.0445 \sim 0.0523$ & $274.6 \sim 377$ & $9.7 \sim 75.1$ & {$[21]$} \\
152.4 & 48.8 & 0.0897 & 347 & 55.1 & {$[26]$} \\
$114 \sim 115$ & $22.9 \sim 30.5$ & $0.0408 \sim 0.0511$ & $343 \sim 365$ & $26.4 \sim 98.4$ & {$[31]$} \\
114.3 & 34.1 & 0.0476 & 287.3 & $32.5 \sim 104.9$ & {$[32]$} \\
152.4 & 92.4 & 0.1216 & 270 & 73 & {$[33]$} \\
$120 \sim 180$ & $79.5 \sim 120.8$ & $0.0666 \sim 0.1911$ & 222.7 & $18.3 \sim 36.4$ & {$[34]$} \\
114.3 & $19.4 \sim 41.7$ & $0.0335 \sim 0.0478$ & $235 \sim 355$ & $56.2 \sim 107.2$ & {$[35]$} \\
$114 \sim 167$ & $20.4 \sim 53.9$ & $0.0305 \sim 0.0808$ & 300 & $45.6 \sim 62.4$ & {$[36]$} \\
112.6 & $19.5 \sim 38.9$ & $0.0286 \sim 0.0684$ & 360 & $21.4 \sim 29.7$ & {$[37]$} \\
$100 \sim 250$ & $25.4 \sim 133.7$ & $0.0449 \sim 0.098$ & $282 \sim 482.5$ & $47.2 \sim 80.2$ & {$[15,38,39]$} \\
$153 \sim 203$ & $51 \sim 67.7$ & $0.0792 \sim 0.1051$ & $318.3 \sim 380$ & $29.8 \sim 63.3$ & {$[40]$} \\
$149 \sim 219$ & $19.9 \sim 165$ & $0.0425 \sim 0.1492$ & $338 \sim 438$ & $32.9 \sim 74$ & {$[16,41]$} \\
110 & 36.7 & 0.0712 & 398 & $44.8 \sim 52$ & {$[42]$} \\
$133 \sim 168$ & $24.5 \sim 50.4$ & $0.0439 \sim 0.0871$ & $325.3 \sim 392.0$ & $34.3 \sim 71.6$ & {$[43]$} \\
$182 \sim 309$ & $63.5 \sim 94$ & $0.0445 \sim 0.0523$ & $312.8 \sim 362.5$ & $46.8 \sim 50.5$ & {$[44]$} \\
$100 \sim 450$ & $15.2 \sim 220.9$ & $0.0304 \sim 0.202$ & $185.7 \sim 834$ & $9.7 \sim 107.2$ & Range \\
\hline
\end{tabular}

Because the initial mechanical parameters of the steel tube were comprehensively considered by $\alpha$. According to the classification provided in EC3 [45] and AISC [46], the cross-section types of the steel tube are divided into six parts based on the $\alpha$, as shown in Figure 12. Depending on $\alpha$ and $f_{\text {cp }}$, the unified various ductile characteristics of the concrete core in the post-buckling stage are shown in Table 4.

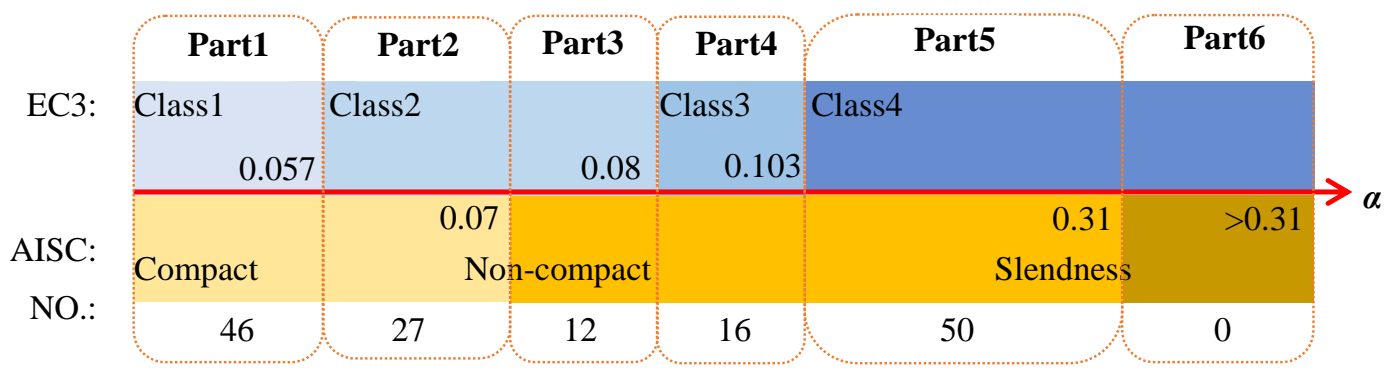

Figure 12. Classification and Limiting Value for the Steel Tubes

In Table 4, ductility and failure types of various CFST sections with increasing $f_{\text {cp }}$ are shown in different colours. The label "A" represents splitting failure of the concrete core, and the label "B" represents shear and sliding failure. The lightest background colour reflects an unlimited growth trend of the strength of the concrete core. The middle colour shows a considerable compressive strength for the concrete core but with obvious damages. The deepest colour means the serious damages of concrete core, the confining effect on which is weak, and the residual capacity of CFSTs is not available. 
Table 4. Ductility and Failure Modes of the Concrete Core of CFSTs in the Post-buckling Stage

\begin{tabular}{lccccc}
\hline \multicolumn{1}{c}{$f_{\mathrm{cp}}$} & $\leq 30 \mathrm{MPa}$ & $30 \sim 40 \mathrm{MPa}$ & $40 \sim 50 \mathrm{MPa}$ & $50 \sim 60 \mathrm{MPa}$ & $>60 \mathrm{MPa}$ \\
\hline Part 1: Class1 \&Compact & A & B & B & B & B \\
Part 2: Class2\&Compact & A & B & B & B & B \\
Part 3: Class2\&Non-Compact & A & B & B & B & B \\
Part 4: Class3\&Non-Compact & B & B & B & B & B \\
Part 5: Class4\&Non-Compact & B & B & B & B & B \\
\hline
\end{tabular}

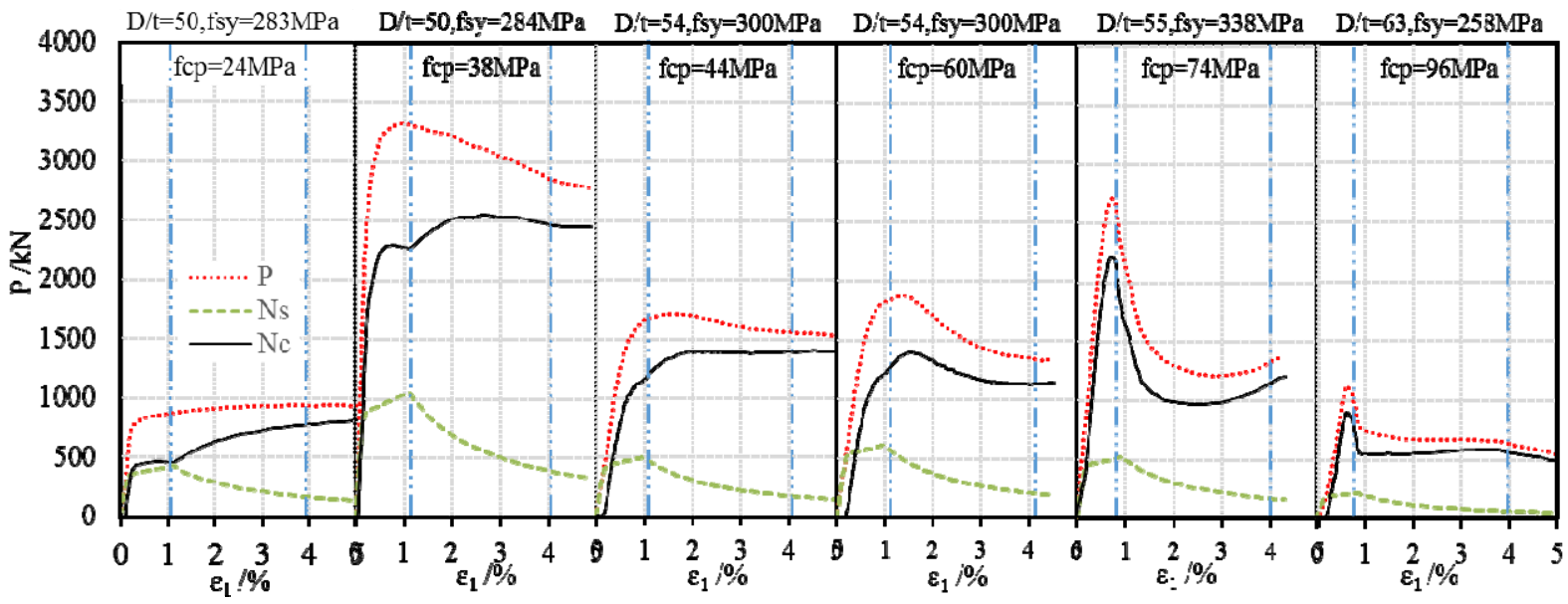

Figure 13. Nominal Performance Curves of the Concrete Core

To provide a clearer variation trend of the concrete ductility, Figure 13 lists a series of nominal performance curves of the concrete core filled in the steel tubes with similar mechanical parameters in black. In Figure 13, the experimental curves of load $P$ and overall axial shortening strain $\varepsilon_{1}$ are shown in red. The bearing capacity of $N_{\mathrm{s}}$ in the green curves are calculated by the following Eq. 9 , in which the $f_{\mathrm{s} 1}$ is based on Eq. 1 to Eq. 3 . And the nominal bearing capacity of concrete $N_{\mathrm{c}}$ is the remaining strength by subtracting the $N_{\mathrm{s}}$ from the axial load $P$.

$N_{\mathrm{s}}=A_{\mathrm{s}} f_{\mathrm{s} 1}$

where $A_{\mathrm{s}}$ is the initial area of the steel tube in CFSTs, $f_{\mathrm{s} 1}$ is the compressive stress of the steel tube.

In summary, the effect of local buckling on the development of concrete compressive strength in the post-buckling stage is clearly reflected. Because of the differences in the dilatation of different strength concrete, a further improvement of the concrete strength is exhibited due to the local buckling if the steel tube is filled in medium and low strength. The improved effect becomes weaker with the increasing unconfined strength of the concrete core.

\section{RESIDUAL BEARING CAPACITY OF CFST}

\subsection{Superposition Method}

Based on the study on confining effect, when the axial shortening strain reaches 0.04 , the confining stress would be stable, which means that the axial bearing capabilities of the steel tube and the 
concrete core are stable as well. Therefore, the residual bearing capacity $N_{\text {res }}$ of the CFSTs can be estimated by the superposition of the two axial bearing capabilities. The paper determines $N_{\text {res }}$ by the superposition method, and the equation is:

$N_{\text {res }}=N_{s, r e s}+N_{c, \text { res }}=A_{s} f_{s, r e s}+\eta A_{c} f_{c c, \text { res }}$

Where $f_{\text {cc,res }}$ represents the confined compressive strength of the concrete core by steel tube. The simplified equation is proposed as follows.

$$
f_{c c, r e s}=K_{c a l} \cdot f_{c p}=f_{c p}+4.1 f_{r, r e s}
$$

Where $f_{\text {r,res }}$ is the confining stress when of the axial shortening stain is 0.04 . Based on the Eq. 5 and von Mises yield criterion shown in Figure $8, f_{\text {r,res }}$ is calculated as follows.

$$
\begin{gathered}
f_{r, r e s}=\frac{2 t}{D-2 t} \alpha_{r e s} f_{s y} \\
\alpha_{r e s}{ }^{2}-R \alpha_{r e s}+R^{2}=1
\end{gathered}
$$

The Eq. 11 is based on the work proposed by Richart [47], which is used to calculate the ultimate compressive strength of the confined concrete. Due to the inevitable damage of the concrete core for most of the CFSTs in the post-buckling stage, a strength reduction factor $\eta$ is introduced in the superposition method. Based on the nominal $N_{\text {c,res }}$ collected from the nominal concrete performance curves of the available CFST tests as shown in Table 3. The nominal $\eta$ can be calculated by $N_{\text {c,res }} /\left(A_{c} f_{\text {cc,res }}\right)$.

According to the Table 4 and the Figure 11, considering the high correlation between the ductility and the compressive strength of the concrete core, the influencing factor $\alpha$ is the best parameter to obtain a reasonable $\eta$. As the Figure 14 shows, a power function relation exists between the upper limit of $\eta$ and $\alpha$, as shown in Eq. 13.

$$
\eta=0.25 \alpha^{-0.5}
$$

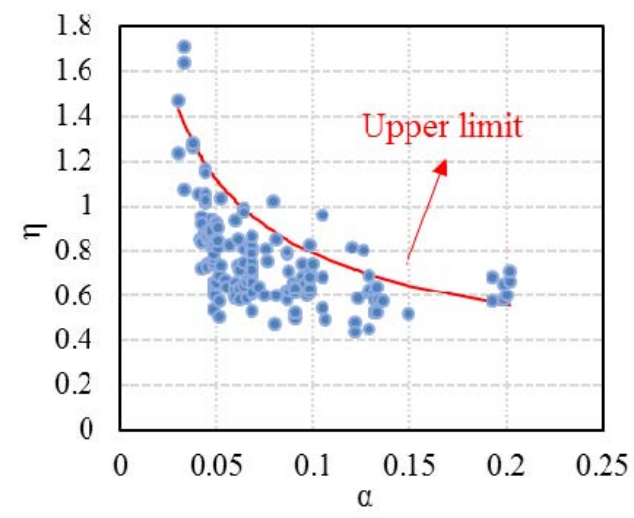

Figure 14. Relationship between $\eta$ and $\alpha$ 


\subsection{Verification of the Proposed Method}

According to the various ductile behaviours of the concrete core shown in Table 4, when the concrete strength $f_{\text {cp }}$ does not exceed $40 \mathrm{MPa}$, the residual capacity of the CFST is outstanding due to the superior ductility. When $f_{\mathrm{cp}}$ exceeds $40 \mathrm{MPa}$, the residual capacity reduces rapidly with the decreasing of $\alpha$. This paper discusses the accuracy of the residual capacity of the CFSTs with the best ductility, as shown in Figure 15. The post-buckling behavior of the concrete core in the CFSTs studied in Figure 15 corresponds to the lightest background in Table 4.

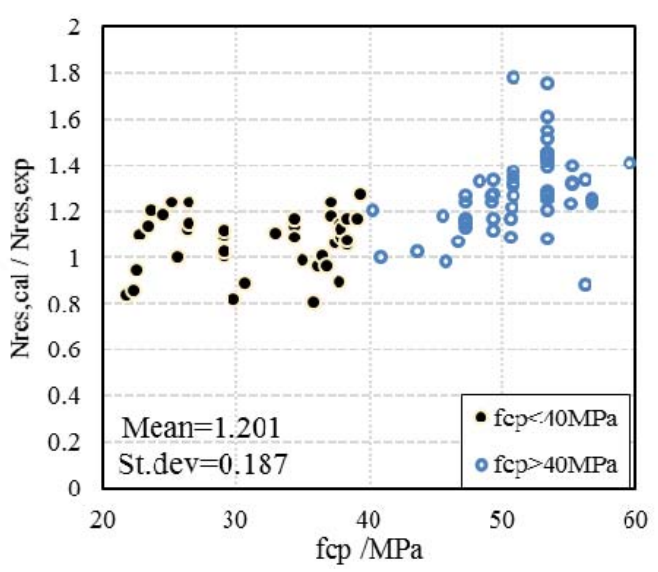

Figure 15. Comparisons between the Calculated and Measured Residual Capacity of CFSTs with the Best Strength Enhancement of the Concrete Core

Generally, the deviation of the ratio of $N_{\text {rea,cal }}$ to $N_{\text {res,exp }}$ mainly concentrated in the range of 0.8 to 1.4 . The average value is 1.201 and the standard deviation is 0.187 . The estimate is more accurate and stable when $f_{\text {cp }}$ does not exceed $40 \mathrm{MPa}$, which is consistent with the ductile characteristics of the CFSTs.

Figure 16 shows all the ratios of $N_{\text {res,cal }}$ to $N_{\text {res,exp }}$ considering the influencing factors of $\alpha$ and $f_{\text {cp. }}$. Obviously and also not surprising, the deviation of $N_{\text {rea,cal }}$ to $N_{\text {res,exp }}$ is also most accurate and stable when $f_{\text {cp }}$ does not exceed $40 \mathrm{MPa}$. On the other side, for the CFST with poor ductility, a scattering of $N_{\text {res,cal }} / N_{\text {res,exp }}$ is observed. The main reasons of the scatting are from the value of $\eta$ and measured residual capability $N_{\text {res,exp }}$, maybe because some of the collected CFSTs were tested by load control, which greatly affects the accuracy in the post-ultimate stage.

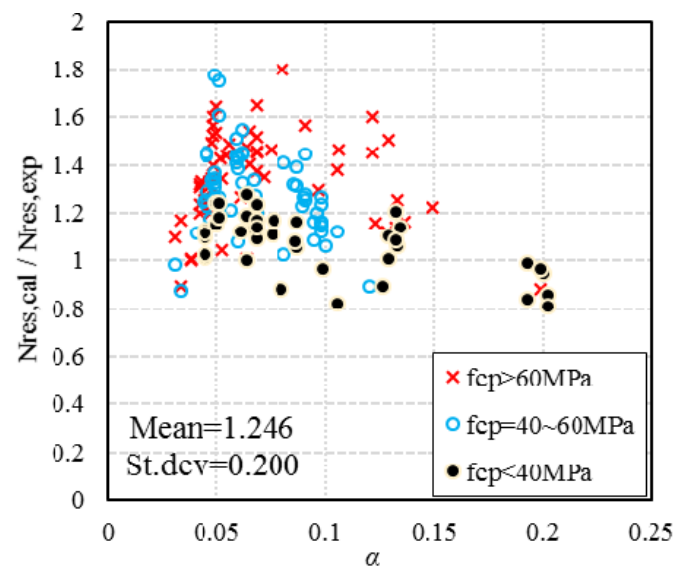

Figure 16. Comparisons between the Calculated and Measured Values of the Residual Capacity for all selected CFSTs 


\section{CONCLUSIONS}

In this paper, the post-buckling behaviour of CFSTs was studied in detail, and the residual capacity of CFSTs was predicted by a superposition method considering the local buckling of steel tube. In summary, the following conclusions can be drawn:

(1) Comparing to the experimental test results, the superposition method can well predict the residual capacity of the CFSTs with normal strength concrete and the thick-walled CFSTs with high strength concrete. However, the accuracy is relative low for the thin-walled CFSTs with high strength concrete.

(2) The local buckling of the steel tube may influence the compressive strength of the concrete core in the post-buckling stage. A further improvement of the concrete strength is exhibited due to the local buckling if the steel tube is filled in medium and low strength concrete. The benefit effect becomes weaker with the increasing of the strength of the concrete core. The effect of the concrete core on the steel tube is the local buckling mode, and the mechanical behaviours of steel tubes in CFSTs under axial compression are similar to that of CHSs.

\section{ACKNOWLEDGMENT}

The authors are grateful for the financial support by the National Key Research and Development Program of China (Grant No. 2016YFC0802205), the National Natural Science Foundation of China (Grant No. 51678504) and Department of Science and Technology of Sichuan Province (Grant No. 2018JY0029).

\section{REFERENCES}

[1] Yu, Z.X., Qiao, Y.K., Zhao, L., Xu, H., Zhao S.C. and Liu, Y.P., "A Simple Analytical Method for Evaluation of Flexible Rockfall Barrier Part 1: Working Mechanism and Analytical Solution", Advanced Steel Construction, 2018, Vol. 14, pp. 115-141.

[2] Xu, H., Gentilini, C., Yu, Z.X., Qi, X. and Zhao, S.C., "An Energy Allocation Based Design Approach for Flexible Rockfall Protection Barrier", Engineering Structures, 2018, Vol. 173, pp. 831-852.

[3] Zhou, F.L., Cui, H.C., Shigetaka, A.B.E., Lv, X.L., Sun, Y.P., et al., "Inspection Report of the Disaster of the East Japan Earthquake by Sino-Japanese Joint Mission", Building Structure, 2012, Vol. 42, pp. 1-20. (in Chinese)

[4] Liu, S.W., Liu, Y.P. and Chan, S.L., "Advanced Analysis of Hybrid Steel and Concrete Frames Part 1: Cross-section Analysis Technique and Second-order Analysis", Journal of Constructional Steel Research, 2012, Vol. 70, pp. 326-336.

[5] Liu, S.W., Liu, Y.P. and Chan, S.L., "Advanced Analysis of Hybrid Steel and Concrete Frames Part 2: Refined Plastic Hinge and Advanced Analysis", Journal of Constructional Steel Research, 2012, Vol. 70, pp. 337-349.

[6] Yu, Z.X., Qiao, Y.K., Zhao, L., Xu, H., Zhao, S.C. and Liu, Y.P., "A Simple Analytical Method for Evaluation of Flexible Rockfall Barrier Part 2: Application and Full-scale Test", Advanced Steel Construction, 2018, Vol. 14, pp. 142-165.

[7] Xu, H., Gentilini, C., Yu, Z.X., Wu, H. and Zhao, S.C., "A Unified Model for the Seismic Analysis of Brick Masonry Structures", Construction and Building Materials, 2018. Vol. 184, pp. 733-751. 
[8] Chen, W.F. and Ross, D.A., "Test of Fabricated Tubular Columns", American Society of Civil Engineers, 1977, Vol. 103, pp. 619-634.

[9] Liu, S.W., Chan, T.M., Chan, S.L., et al. "Direct Analysis of High-strength Concrete-filled-tubular Columns with Circular \& Octagonal Sections", Journal of Constructional Steel Research, 2017, Vol. 129, pp. 301-314.

[10] Zhao, H., Sun, Y.P, Takeuchi, T. and Zhao, S.C., "Comprehensive Stress-strain Model of Square Steel Tube Stub Columns under Compression", Engineering structures, Vol.131, pp. 503-512.

[11] Yang, C., Zhao, H., Sun, Y.P. and Zhao, S.C., "Compressive Stress-strain Model of Cold-formed Circular Hollow Section Stub Columns Considering Local Buckling". Thin-walled Structures, 2017, Vol. 120, pp. 495-505.

[12] Cao, B.Z., Zhang, Y.C., Wang, Q.P., et al. "Mechanical Behavior of Circular Concrete Filled Thin-walled Steel Tube Stub Columns", Journal of Harbin Institute of Technology, 2005, Vol. 37, No. 8, pp. 141-144. (in Chinese)

[13] Tan, K.F., Pu, X.C. and Cai, S.H., "Study on the Mechanical Properties of Steel Extra-high Strength Concrete Encased in Steel Tubes", Journal of Building Structures, 1999, Vol. 20, No.1, pp. 10-15. (in Chinese)

[14] O’Shea, M.D. and Bridge, R.Q., "Tests on Thin-walled Concrete-filled Steel Tubes", Twelfth International Specially Conference on Cold-formed Steel Structures, St. Louis, Missouri, U.S.A., 1994, pp. 399-419.

[15] Han, L.H., Yao, G.H. and Zhao, X.L., "Tests and Calculations for Hollow Structural Steel (HSS) Stub Columns Filled with Self-consolidating Concrete (SCC)", Journal of Constructional Steel Research, 2005, Vol. 61, No. 9, pp. 1241-1269.

[16] Yu, Z.W., Ding, F.X. and Lin, S., "Researches on Behavior of High-Performance Concrete Filled Tubular Steel Short Columns", Journal of Building Structures, 2002, Vol. 23, No. 2, pp. 41-47. (in Chinese)

[17] Johansson, M. and Gylltoft, K., "Mechanical Behavior of Circular Steel-Concrete Composite stub columns", Journal of Structural Engineering, 2002, Vol. 128, No. 8, pp. 1073-1081.

[18] Sakino, K., Nakahara, H. and Morino, S., et al., "Behavior of Centrally Loaded Concrete-filled Steel Tube Short Columns", Journal of Structural Engineering, ASCE, 2004, Vol. 130, No.2, pp.180-188.

[19] Wang Y.Y. and Zhang, S.M., "Research on Basic Behavior of High-strength Concrete-filled Steel Tubular Short Columns under Axial Compressive Loading", Journal of Harbin Institute of Technology, 2005, Vol. 37, pp.100-103. (in Chinese)

[20] O’Shea, M.D. and Bridge, R.Q., "Local Buckling of Thin-walled Circular Steel Sections with or Without Internal Restraint", Journal of Constructional Steel Research, 1997, Vol. 41, No.2/3, pp. 137-157.

[21] Cai, S.H. and Jiao, Z.S., "Behavior and Ultimate Strength of Short Concrete-filled Steel Tubular Columns", Journal of Building Structures, 1984, Vol. 5, No. 6, pp. 13-29.(in Chinese)

[22] Fujimoto, T., Mukai, A. and Nishiyama, I., et al., "Axial Compression Behavior of Concrete Filled Steel Tubular Stub Columns using High Strength Materials". Journal of Structural \& Construction Engineering, AIJ, 1997, Vol. 62, No. 498, pp. 161-168. (in Japanese)

[23] Zhou, X.H., Liu, J.P. and Zhang, S.M., "Behavior of Circular Tubed Reinforced Concrete Stub Columns under Axial Compression", Engineering Mechanics, 2009, Vol. 26, No. 11, pp. 53-59.

[24] Zhang, S.M., Liu, J.P., Ma, L. and Xing, T., "Axial Compression Test and Analysis of Circular Tube Confined HSC Stub Columns", China Civil Engineering Journal, 2007, Vol. 40, No.3, pp. 24-31, 68. (in Chinese)

[25] Wang, Y.Y. and Zhang, S.M., "Influencing Factor Analysis on Failure Modes of Concrete-filled Steel Tubular Stub Columns Subjected to Axial Compression", Journal of Harbin Institute of Technology, 2005, Vol. 37, No. 8, pp. 133-136. (in Chinese) 
[26] Fam, A., Frank, S.Q. and Rizkalla, S., "Concrete-filled Steel Tubes Subjected to Axial Compression and Lateral Cyclic Loads", Journal of Structural Engineering, 2004, Vol. 130, No. 4, pp. 631-640.

[27] Johansson, M., "The Efficiency of Passive Confinement in CFT Columns", Steel and Composite Structures, 2002, Vol. 2, No. 5, pp. 379-396.

[28] Sakino, K., Tomii, M. and Watanabe, K., "Sustaining Load Capacity of Plain Concrete Stub Columns Confined by Circular Steel Tubes", Proceedings of the International Specialty Conference on Concrete-filled Steel Tubular Structures, ASCCS, Harbin, China, pp. 112-118.

[29] O'Shea, M.D. and Bridge, R.Q., "Test on Circular Thin-walled Steel Tubes Filled with Medium and High Strength Concrete", Department of Civil Engineering Research Report No. R755, Sydney, 1997.

[30] Orito, Y., Sato, Y. and Tanaka, N. and Watanabe, Y., "Study on Unbonded Steel Tube Concrete Structures", Composite Construction in Steel \& Concrete, ASCE, 2010, pp. 786-804.

[31] Ellobody, E., Young, B. and Lam, D., "Behavior of Normal and High Strength Concrete-filled Compact Steel Tube Circular Stub Columns", Journal of Constructional Steel Research, 2006, Vol. 62, No. 7, pp. 706-715.

[32] Oliverira, W.L.A.D., Nardin, S.D., Ana Lúcia H. de Cresce El Debs, et al., "Influence of Concrete Strength and Length/ Diameter on the Axial Capacity of CFT Columns", Journal of Constructional Steel Research, 2009, Vol. 65, No. 12, pp. 2103-2110.

[33] Prion, H.G.L. and Boehme, J., "Beam-column Behavior of Steel Tubes Filled with High Strength Concrete", Canadian Journal of Civil Engineering, 1994, Vol. 21, No. 2, pp. 207-218.

[34] Cao, B.Z., Zhang, Y.C., Wang, Q.P., et al, "Mechanical Behavior of Circular Concrete Filled Thin-walled Steel Tube Stub Columns", Journal of Harbin Institute of Technology, 2005, Vol. 37, pp. 141-144. (in Chinese)

[35] Ekmekyapar, T. and AI-Eliwi B.J.M., "Experimental Behaviour of Circular Concrete Filled Steel Tube Columns and Design Specifications", Thin-walled Structures, 2016, Vol. 105, pp. 220-230.

[36] Abed, F., Alhamaydeh, M. and Abdalla, S., "Experimental and Numerical Investigations of the Compressive Behavior of Concrete Filled Steel Tubes (CFSTs)", Journal of Constructional Steel Research, Vol. 80, No. 1, pp. 429-439.

[37] Gupta, P.K., Sarda, S.M. and Kumar, M.S., "Experimental and Computational Study of Concrete Filled Steel Tubular Columns under Axial Loads", Journal of Constructional Steel Research, 2007, Vol. 63, No. 2, pp. 182-193.

[38] Han, L.H. and Yao, G.H., "Experimental Behaviour of Thin-walled Hollow Structural Steel (HSS) Columns Filled with Self-consolidating Concrete (SCC)", Thin-walled Structures, 2004, Vol. 42, No. 9, pp. 1357-1377.

[39] Han, L.H., Tao, Z. and Wang, W.D., "Advanced Composite and Mixed Structures-Testing, Theory and Design Approach", China Science Publishing \& Media Ltd, 2009. (in Chinese)

[40] He, F., Zhou, X.H., and Tang, C.H., "Experimental Research on the Bearing Behavior of High-strength-concrete-filled Steel Tube under Axial Compression", Engineering Mechanics, 2000, Vol. 17, No. 4, pp. 61-66. (in Chinese)

[41] Yu, Z.W., Ding, F.X. and Cai, C.S., "Experimental Behavior of Circular Concrete-filled Steel Tube Stub Columns", Journal of Constructional Steel Research, 2007, Vol. 63, No. 2, pp. 165-174.

[42] Ke, X.J., Chen, Z.P., Ying, W.D., et al., "Experimental Study on the Axial Compression Performance of High-strength Concrete Filled Steel Tube Columns", Building Structure, 2014, Vol. 44, No. 16, pp. 46-49, 76. (in Chinese) 
[43] Zhang, S.M. and Wang, Y.Y., "Failure Modes of Short Columns of High-strength Concrete-filled Steel Tubes", China Civil Engineering Journal, 2004, Vol. 37, No. 9, pp. 1-10. (in Chinese)

[44] Tian, Y., "Experimental Research on Size Effect of Concrete-filled Steel Tubular Stub Columns under Axial Compressive Load", M.A. Thesis, Harbin Institute of Technology, 2014. (in Chinese)

[45] Eurocode 3, "Design of Steel Structures. Part 1-1: General Rules and Rules for Buildings", CEN, Brusseles, 2005.

[46] American Institute of Steel Construction (AISC), "Specification for Structural Steel Buildings", Chicago, 2010.

[47] Richart, F.E., Brandtzaneg, A. and Brown, R.L., "A Study of the Failure of Concrete under Combined Compressive Stresses", Bulletin 185, University of Illinois Engineering Experimental Station, 1928, Vol. 26, No. 12. 